\title{
Gender and the transsexual body in Transamerica
}

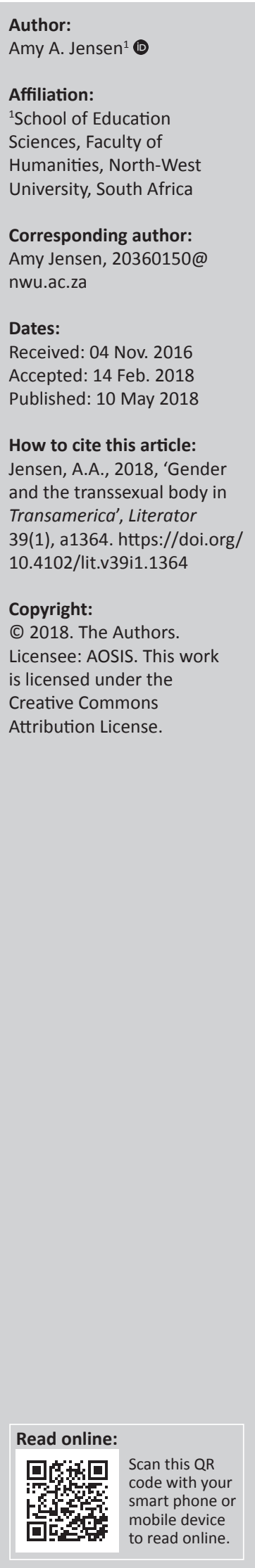

Transamerica, by Duncan Tucker, released in 2005, addresses lesbian, gay, bisexual, transgender and queer- (LGBTQ-) related themes through a transsexual female protagonist, Bree. This article discusses the film as an important step in the direction of representing the complexity of gender, which, by today's standards, is more generally appreciated. Because of its subject matter, Transamerica is a contentious film, lauded and condemned in mainstream media for how it dealt with and represented transsexual identities. Despite nominations for a number of awards, the film's portrayal of transsexual identities was largely ignored in academic discourse at the time. I argue here that the film provides insight into the challenges, requirements, concerns, as well as the consequences of gender-fluid expression, which has been recognised in academia for years and has become a more discussed topic in mainstream society, but the manner in which the film examines these insights was overlooked. I do this by contextualising the film in terms of contemporary examples of transgender existence, which have brought the topic to mainstream discourse, and by applying gender theory concepts to the film. I discuss the protagonist's physical and emotional journey to selfdiscovery in the context of the road movie trope. I then look into the protagonist's gender performance, as well as how the protagonist negotiates this performance in the various places she visits while on the journey. I show that the film encourages open and honest discourse about gender identity and expression; the opportunity for this discussion was not taken in the year of the film's release.

\section{Introduction}

Insight into the life of a male-to-female transsexual is provided in Duncan Tucker's Transamerica, released in 2005. Although the film was nominated for and won a number of awards, ${ }^{1}$ it received little attention in academic discourse. The academic recognition the film did receive, includes a comparison of the portrayal of romantic love in this and other 'trans-films' (Abbott 2012) and how paratext (film reviews, movie posters and director commentary) can 'validate, and celebrate lesbian, gay, bisexual and transgender (LGBT) life and subjectivity' (Cavalcante 2013). Although the discourse on gender goes far back in history and has a solid academic grounding, there is no focus in academia on how this specific film provides insight into gender constructs and transsexuals. However, in light of a number of recent instances that have highlighted the shifting landscape in gender studies, particularly in terms of transgender existence and the fluidity of gender, the topic has become popular, as can be seen in contemporary American society in this part of the 21st century. Examples include the publicised transformation of Bruce to Caitlyn Jenner in the USA, in 2015. ${ }^{2}$ The fact that someone with such a high profile was open about her new identity, and then won an award for 'Woman of the Year', generated various publicised discussions on this complex notion of gender and gender identity. A more recent example is President Trump's 2017 ban of transgender individuals in the military, which has generated many discussions in terms of participation of transgender individuals in society. Another example is a 2017 episode of Survivor in which a contestant was 'outed' for being a transsexual. Although the backlash was in favour of Zeke Smith (the transgender contestant), it indicates that gender complexities are relevant in society and need to be discussed in a mature, open and honest manner. Tucker's film provided insight into this gender-fluid existence before it became the highly popular and contested topic it is today. Academia did not seize the opportunity in 2005 to highlight the fluid nature of gender as it is represented in Transamerica. The opportunity for an open and honest discussion on gender complexities as portrayed in the film was not taken by the media or academia.

The film's protagonist is a presurgery male-to-female transsexual, Bree (Felicity Huffman), who travels by road from New York to Los Angeles, with a newly discovered son, Toby (Kevin Zegers).

1.The actress who plays the protagonist won a Golden Globe, an Independent Spirit, an award from the National Board of Review and an award from the International Press Academy (Greenblatt 2006).

2.Jenner has been fiercely criticised by the transgender community for various reasons, from her privileged position as a wealthy, white woman to her vote for Donald Trump as president. 
The journey is a prerequisite from Bree's therapist, Margaret, before she will give her final permission for the sexual reassignment surgery. On first meeting Toby, to bail him out of jail, Bree does not disclose her true identity or the fact that she is a transsexual woman but instead poses as a Christian social worker, thereby learning about the boy's life. As with all road movies, the pair face many obstacles as they travel. These obstacles include Bree's discovery that Toby's stepfather is abusive; Toby's discovery of Bree's transsexuality; their vehicle being stolen and Bree being forced to make contact with her estranged parents; and Toby running away from Bree's parents' house. By the end of the film, Bree undergoes surgery and Toby reunites with her at her home.

The writer and director of the film, Duncan Tucker, comments in the additional material section on the DVD that the film is not about transsexuality, but rather 'about growing up. It's about finding yourself and learning to love yourself, and about accepting yourself [...] and through that, being able to love others' (Transamerica DVD). However, by the end of the sometimes difficult journey, and the film, the audience has gained insight into the challenges, concerns and requirements of transsexual individuals. The film is not without criticism for example, social media has criticised the motive of using a female actress for the portrayal of a transsexual woman. However, the insights that the narrative offer remain. When this film is compared to other films with transsexual protagonists, such as The crying game (Jordan 1992) and Boys don't cry (Peirce 1999), it departs from these darker, gender violent stories, ${ }^{3}$ with a light-hearted plot portraying the everyday life and relationships of a transgender individual. The narrative deviates from the consequences of queer romantic relationships as the salient theme and rather focuses on the quotidian, providing insight into the transition, concerns and challenges of a gender-fluid individual. Thus, the film manages to represent the complex and dynamic process of the rejection and acceptance of gender and sex according to cultural and societal norms and in the process comments on gender as a construct. The notion of body and self-acceptance is also part and parcel of self-discovery. This study of Transamerica aims to expose how this film provided a window into the complexities of gender and gender expression in the 21st century before a greater awareness and willingness for the discussion of the topic became more normative. As such, this film was a forerunner for recent discourse on gender fluidity, in terms of the processes, concerns and experiences of a transsexual individual.

Taking its cue from the film's title, this article has a two-foci approach to analysing Transamerica: the prefix trans- refers to not only the cross-country journey but also the transition from one sex to another. According to Hayward (1996:300), one of the codes of road movies is discovery, usually self-discovery of the characters. The mobile body offers the opportunity for the characters to deal with internal and/or external conflict, while negotiating various destinations. This article discusses

3.Brokeback Mountain (Lee 2005) deals with similar gender violence against gay men and was better received in academia than Transamerica, although the films were released in the same year. It is interesting to note that academics did not pay much attention to a film that breaks away from romantic love against the backdrop of violence. the journey on the road in order to expose the complexities of gender and gender expression by focusing on the transsexual protagonist. The analysis focuses on the protagonist's progression to 'become a woman' (de Beauvoir 1988:259). The structure is as follows: first, a theoretical overview will provide definitions from transgender studies. It will also render details on iconography and performativity, as well as explain chronotopes of the road. Next, a close analysis of the film in terms of the theory will be presented. Initially, the focus is on the stereotypes that Bree uses to portray herself as a woman. It also considers what the journey offers in terms of encounters on the road, and what these encounters represent in terms of gender in society. The paper concludes by showing how the film, finally, uses the transsexual body and the experiences on the road to expose transgender concerns, challenges and requirements. These aspects need to be acknowledged in order to have mature discussions on gender complexities and the fluid nature of gender, in an open and honest manner, particularly because this film does so in a light-hearted and humorous manner. The film renders an opportunity for discourse on gender complexities and, although 2005 was not that long ago, the opportunity to analyse the film's portrayal of transsexual representation was missed by academia.

\section{Theoretical exposition}

To probe Bree's journey in terms of the various expressions of gender in society, the following definitions from transgender studies must be established. In terms of binaries, there is a polarised distinction within the concepts of sex and gender. Sex is a physical aspect related to biology, that is, anatomy, hormones and physiology, while gender is constructed through social, psychological and cultural means (West \& Zimmerman 1987:125). Gender binaries call for a 'one or the other' approach to these two options, rather than acknowledging a continuum of gender identities or expressions (Green \& Maurer 2015:53). The term transgender is used as an adjective to qualify a person whose gender identity does not match the biological sex assigned to them at birth (Green \& Maurer 2015:56). The term can encompass a range of identities and now includes the older term transsexual, which has been used to denote a person who has had hormonal or surgical interventions on the body to align with their gender identity rather than the sex they were assigned at birth (Green \& Maurer 2015:56). This article uses the older term transsexual because the narrative centres on the protagonist's journey with the ultimate destination of her sexual reassignment surgery. When the term transgender is used, it pertains to the variety of identities on the gender continuum. The latter term is connected to gender fluidity. The phrase genderfluid references someone whose gender identity or expression shifts between man/masculine and woman/feminine or can fall somewhere along the continuum (Green \& Maurer 2015:54). Nagoshi and Brzuzy (2010) explain that:

\footnotetext{
... transgenders differ widely in their degree of belief in the fluidity of gender identity. Some accept such fluidity only to the extent that one can switch between two otherwise separate, essentialist, and pure gender categories, whereas others believe that an embodied gender identity is still highly malleable. (p. 432)
} 
It is interesting to note that even among transgender individuals there is no definitive manner to express gender; it is a complex notion because it manifests in various ways in different cultures. In the analysis, Bree's alignment with the former essentialist version of gender-fluid identity is discussed in order to provide insight into transsexual existence. Although for many years this information has been used by academics and the LGBTQ community, this film provides insight into the processes and concerns of transsexuals to a wider mainstream audience.

'Gender expression', according to Green and Maurer (2015:54), is a person's outward gender representation, comprising personal style, clothing, hairstyle, jewellery, vocal inflection and body language. These elements have been discussed many times in gender studies literature for a number of years. For example, Tauches (2006:174) explains the notion of gender as a 'social construction that arises from biological sex; it consists of socially defined behaviours and traits that are considered normal for each sex'. This explanation is reminiscent of what West and Zimmerman (1987) refer to as 'doing gender' and what Butler (1988) refers to as 'performativity'. Butler (1988:523) suggests that the body becomes its gender via a series of acts that are 'renewed, revised, and consolidated through time'. Butler (1988:520) argues that because gender might be understood as constituted, it is capable of being constituted differently. There is a definite link to gender fluidity and Butler's, and these other theorists', concepts. O'Reilly (2009:8) points to the fact that 'the body has become more visible as a challenge to constricting social codes, through the adoption of piercings, tattoos and other modifications', including plastic surgery. Bree is closely related to social codes and this study analyses how she uses them in her performance as a hyper-feminine woman. The fact that this article deals with the fictive lifeworld of a transsexual protagonist in a film calls for cinematic vocabulary to be used. For example, in film, such visual codes are termed iconography.

Iconography, according to Ryall (1998:331), is concerned with the 'distinctive visual qualities' of a specific film genre, including settings, costumes, actors/characters, characteristic props and other specifics such as modes of transport and weaponry. One of the iconographic elements is the physical body. Waskul and Vannini (2006:10) explain that through the body, we perform, express and represent subjectivity, and through these same activities others 'judge our body as object by means of appearance and performance'. Connected to the idea of the outer appearance is how one presents oneself to the world, which includes the manner in which one dresses. Stutesman (2005:28) observes that a character's costumes indicate who he or she is, how that character feels or even where he or she is going in the world. Viewers can deduce a character's inner workings from analysing that character's outer appearance. Stereotypes work with iconography in fictions to express visual or non-verbal aspects of a particular character. In Transamerica, the female protagonist uses stereotypes consciously and deliberately to perform her female gender and to become a woman. Therefore, the concepts expressed in real-world gender studies can be analysed via the iconography of this film.

The phrase cinematic journey includes any type of journey taken in a film. Eleftheriotis (2010:99) refers to cinematic journeys as 'visual explorations of travelled space with investigations of psychological processes of change and transformation'. This change can take the form of altered beliefs or even challenges to preconceived ideas of the self, as the traveller moves through the world and interacts with its inhabitants. The term encompasses the road movie. This genre centres on the protagonists' journey, particularly their inner journey to self-discovery. Laderman (2002:79) acknowledges that 'driving across an external landscape is usually a metaphor for a journey across an internal, personal space'. Ganser, Pühriner and Rheindorf (2006:2) use Bakhtin's chronotopes of the road to explore how configurations of time and space are represented in the road movie genre. According to Ganser et al. (2006), film is a:

... socially determined set of practices, no less than the experience of everyday life, [it] constructs spaces and places according to specific chronotopes, these, in turn, do not exist in a social void but interact with and depend on a number of other realities such as gender, race, and class. (p. 5)

They explain that Bakhtin believed that the emergence of recognisable chronotopes within a narrative offers the audience an opportunity to endow the causal chain (or lack thereof) with their own values. The chronotope that will be applied is the chronotope of the road as setting, as it functions as a meeting place for characters that may never have had an opportunity to meet. Therefore, the manner in which time and space are configured in this film in order for various encounters on the road to occur can shed light on gender complexities in our society. This information and attitude is more generally accepted in today's society; however, the film was largely ignored at the time of its release.

\section{Bree's gender expression}

Bree is a male-to-female transsexual who actively seeks to alter her body and physical identity over a period of time, in order to be seen and acknowledged, in binary terms, as the opposite sex. The film's iconography in terms of Bree and her environment represents her as a hyper-feminine woman. In the opening sequence of the film, when the audience is first introduced to Bree, she has already had electrolysis, hormone therapy for 3 years, facial feminisation surgery, a brow lift, a forehead reduction, jaw re-contouring and a tracheal shave. All the physically traditional female visual indicators are in place. Bree undergoes these operations and taps into stereotypes to make herself appear as a woman. She is already far along in her transition; it is only suggested that the numerous operations would have been lengthy and painful. In her gender expression, she assumes attire that is almost to the point of being overly feminine in terms of 
colour choices and clothing items. She puts on stockings, a brassiere in which she also places breast prostheses, control underwear to tuck her penis away, and a pink skirt suit. This gender expression is a cliché of that of a genteel lady in the 1950s rather than a woman who may wear trousers or any clothing she chooses. This cliché is especially apparent in her choice of predominantly pink clothing and house decor and its association with femininity. Once dressed, she reapplies pastel pink nail polish to her long nails, brushes her hair and applies her make-up in the mirror. The fact that Bree's reflection is seen in the mirror creates the idea that she needs it to constitute herself as a woman, and it reflects her desire to be female. Merskin (2007:598) explains that when a woman 'puts on her face' she is among other things 'acting in line with social prescriptions of feminine beauty'. Simone de Beauvoir's (1988) famous axiom, 'one is not born, but rather becomes, a woman', is reflected in this scene. Bree's actions and manner of dressing are in line with the stereotypical, heteronormative social expectations of what a woman should look like. This representation of the feminine links to Butler's (1988:523) notions of performativity: Bree is able to use the stereotypes for her gender performance as a woman. These aspects of gender expression are not innate to women; they are learnt behaviours. Therefore, gender is a complex notion because it is influenced by culturally specified and specific performances.

Namaste (2006:180) refers to the 'need to pass' among transsexual men and women, which is about presenting oneself as a man or woman whose original sex is never questioned or suspected. Transsexuals often feel the need to pass in order to avoid harassment; therefore some transgender individuals adhere to binary oppositions and behave and live as one or the other gender. The threat of violence might be the reason that there are transgender people who believe only in the fluidity of gender in terms of binaries. The fact that she still has a penis makes her uncomfortable in her own body. The eye-level camera angle and predominant long shots show how Bree is uncomfortable, insecure and uncertain in her interaction with the people in her environment. She even bends her knees slightly when standing next to a short man, in order to 'blend in'. She tries exceptionally hard not to raise any form of suspicion in terms of her transition. Bree's discomfort even causes her to conceal her transition from Toby. A result, in this film, of open discourse not occurring between Toby and Bree, is Toby 'outing' Bree in front of an unknown man, once he discovers her transsexual identity. Although he initially calls her 'a freak', during a later conversation between the two she asks him if he still thinks that she is a 'freak'. His reply is, 'you're not a freak. You're just a liar'. His reaction is more to Bree's dishonesty in concealing the information. It is refreshing that this film promotes the acceptance of gender-fluid identities. Toby does out Bree from a frustrated and reactive standpoint as this element was concealed from him, even though there were numerous opportunities for Bree to have the discussion. This is once again the call for open and honest discourse on gender-fluid identities.
Another example of these repeated gender acts is when Bree is in Phoenix, at her parents' home. The audience is introduced to Elizabeth, Bree's mother, who is hostile and rude to Bree. Elizabeth reprimands her for coming to the house but pulls her inside so that the neighbours do not see her. Unexpectedly, and perhaps unwittingly, Bree models her appearance, behaviour and mannerisms on her mother, even though they do not get along. They dress in similar pastel colours and in matching suits. They paint their nails and ensure that their hair is styled in a certain way. The two women even take the same female hormone replacement pills. In Butler's (1988) terms, Bree's expression of feminine gender identity is constituted according to existing directives associated with her mother. Elizabeth's gender expression complies with social expectations. Her performance of gender is done well and made to reflect an essentialist gender identity (Butler 1988:528). Therefore, Bree's expression of gender identity is based on something that has been proven as socially accepted and acceptable. Once again the complexities of gender are brought to the fore, as a performative act. Individuals can interpret their own performances in a variety of ways. It is in a binary society that these varieties of performances are judged as 'right' or 'wrong' instead of merely existing on a continuum.

After the opening sequence of the film, Bree answers a series of questions asked by a psychiatrist. One of these is, 'How do you feel about your penis?', to which Bree replies, '[i]t disgusts me. I don't even like looking at it'. From the start, it is clear that she does not like what remains of her male body. The doctor informs her that the American Psychiatric Association categorises gender dysphoria as a very serious mental disorder. Tauches (2006:178) explains that, ' $[\mathrm{m}] \mathrm{any}$ in the field of psychology still view transgendered individuals as mentally ill, diagnosing those who seek help as having "gender dysphoria" or a gender identity disorder'. The American Psychiatric Association (1994:532-533) qualifies that there are two components to gender identity disorder. The first is a strong and persistent cross-gender identification, and the second is evidence of persistent discomfort concerning one's assigned sex or gender role. Many psychologists recommend a sex change through sexual reassignment as the main way to ' $\mathrm{fix}^{\prime}$ ' transgendered individuals, to realign sex and gender in a normal (binary) order. Bree responds to the doctor's comment by saying: 'Don't you find it odd that plastic surgery can cure a mental disorder?', because she feels that after she has had surgery she will be a happier person. This scene provides insight into the requirements of those who are transsexual, while reflecting how society is comfortable with sex binaries and clear distinctions between male and female. Society prefers binaries to fluid identities, and there is a commonly held belief that transsexuals actually mutilate their bodies when they undergo sexual reassignment (Stryker 2006:1). However, not just transsexuals are concerned with their physical appearances. Lips (2006:79) confirms that girls and women all over the world have been taught to focus on their bodies and appearances. This concept of 'body as object', which is 
capable of being physically altered, is similar to many individuals in the 21st century who have plastic surgery and modify their bodies at will. It is not just transsexuals who delve into painful and dangerous interventions of the body but women and men all over the world. Therefore, Bree has the same concerns as many women and men, except the social reaction to these concerns differ in that transsexuals first have to be diagnosed with a mental illness before they can undergo their surgery. It calls into question why the same diagnosis is not given to a person who wants to undergo surgery for cosmetic reasons. This lack of equality again affirms society's comfort in and preference for sex and gender binaries. At the same time, the film makes clear the regimen that a transsexual must undergo and hints to one possible reason for Bree's non-acceptance of herself, because society and psychologists emphasise this fact by first diagnosing her with a disorder. It is only in this part of the 21st century that discussions of transgender identities are taking place. However, many societies still prefer individuals to conform to these binaries in order to be accepted as a legitimate member of society. What is interesting is that the cisgendered person, whose gender identity matches the biological sex assigned at birth (Green \& Maurer 2015:52), does not get questioned about his or her genitals. The concepts of propriety and privacy suddenly become public when someone does not conform to gender binaries. This film opened up the (missed) opportunity to discuss and promote a better understanding and acceptance of gender complexities and 'grey areas of gender', in which individual's right to privacy should be respected.

\section{The cinematic journey on the road}

The viewer is made aware that the amount of ground covered by the protagonists represents time that they spend together in the vehicle. It is fitting that the pair travel by vehicle, as Osteen (2008:184) explains that it signifies 'freedom from rules and the dream of forging a new self'. This forging of a new self is realised throughout the journey. It is a fitting cinematic metaphor for the changes that Bree is undergoing. The road offers the chance for encounters that may not have occurred otherwise - this is one chronotope of the road. Some of the encounters serve to highlight perceptions of gender in society and reflect on the changes Bree is undergoing, but at the same time these encounters also provide examples of spaces in which gender complexities are acknowledged.

In Arkansas at a roadside restaurant, the Ozark Mountain House, a little girl turns around in her chair and stares at Bree. When Bree fully acknowledges the stare, the little girl asks: 'Are you a boy or a girl?' This question reflects society's binary and essentialist perception of sex and gender. The little girl is not malicious in her question but rather reflects curiosity. This type of curiosity in society, although it promotes binaries, is an opportunity to openly discuss the complexity of gender fluidity. The little girl's mother simply dismisses her daughter's question by instructing her to 'stop bothering people'.
This action imitates a portion of society who simply ignore gender complexities. It also dismisses much-needed discourse on complex gender expression and identity. However, in the real world, in the future, perhaps these questions from people and discussions about gender may not be necessary, because in countries like Sweden there are gender-neutral spaces, such as their 'gender-neutral' preschools (Hebblethwaite 2011). Therefore, gender complexities are being acknowledged in the real world, even if only in a few select places. This encounter is connected to a chronotope of the road, although this question can be asked in any and all places.

Another encounter on the road takes place at Mary Ellen's home in Dallas. Her home is an example of a space in which gender fluidity is apparent, acceptable and participants are openly engaged in discourse of sex and gender complexity. This is where Bree and Toby stay with Mary Ellen. She is hosting a 'Gender Pride President's Day Weekend Caribbean Cruise Planning Committee' get-together. All the attendees talk openly about their sex and sex changes. For example, an attendee openly admits, '[w]e are not gender challenged. We are gender gifted. I've been woman and I've been man, and I know more things than you single sex people can even

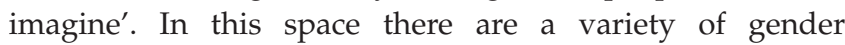
expressions that represent gender as a spectrum, rather than as a set of simple binaries. Bree is shocked by this unexpected openness and says to her host, 'Margaret said you were stealth' (meaning that you blend into everyday society and no one knows that you are a transsexual). Mary Ellen replies, 'I am. In public, but this is the privacy of my own home', where she does not conceal her transsexual identity. When Mary Ellen is talking casually to Bree, she says that Margaret has told her about Bree's operation. Bree replies, 'Toby doesn't know about me'. Mary Ellen looks at her in disbelief and says: 'You're stealth to him? Don't worry, honey, we've all been there'. Bree even hides behind a disapproving mask when she says to Toby, 'Listen, I'm sorry about those ersatz women'. When Toby does not understand the term ersatz, Bree explains that it means 'phony. Something pretending to be something it's not'. Bree is behaving in the same manner; however, she is not honest about it. She not only distances herself from the penis and male but also from others like her by aligning to something she thinks Toby finds agreeable. However, Toby is comfortable in Mary Ellen's home; he engages and seems comfortable in the presence of genderfluid individuals. Toby does eventually out Bree, in a reaction to her dishonesty; considering Toby's character, if an open and honest discussion had taken place, the situation might have been avoided entirely. This concealing of identity is a concern and a consequence of transsexuality. As mentioned before, reactions within societies are varied (from acceptance to violence), but an open and honest discussion is sometimes neglected.

Bree finally has her surgery, after which she becomes a more secure and confident person. This confidence is reflected at the end of the film when Bree is dressed in looser, lighter and more revealing clothing than she has worn throughout the film. 
She becomes a noticeable waitress at the restaurant where she once was a hidden away dishwasher. In the long shots of her, she walks around the restaurant in a more relaxed manner, no longer in an overly upright way. It shows how she is no longer avoiding people but is more comfortable within herself. Although she has a new sense of confidence, her actions indicate that she plays another role in ongoing performativity. The ending of the film represents a positive outcome as well as a positive representation of transsexual experience. This is the perfect film to begin discussions on gender fluidity for young and more mature audiences. Although transphobia and gender violence are still a reality, they are not the only reality of transgendered individuals. This film portrays a positive discourse of trans-existence that was not fully explored or appreciated academically at the time of its release.

\section{Conclusion}

The body is able to express a great deal about the individual who inhabits it. Film has created a space from which the viewer can deduce meanings about a character by analysing the iconography. In Transamerica, Bree's body is expressive of her inner workings. Although she chooses to strategically align to binaries, she still represents the complex nature of gender and gender expression.

The film also offers a glimpse into some of the spaces in which transgender individuals interact with society. The film works to expose the complex nature of gender and expression, in which a person adheres to or rejects certain performances of that gender. It is when society acknowledges and accepts that sex and gender cannot only be perceived in terms of binaries, and that it exists on a spectrum, that the acceptance of gender-fluid individuals can occur. This film was a forerunner for recent discourse on gender fluidity, the processes and the experiences of transsexual individuals.

\section{Acknowledgements}

The author would like to thank all who have contributed to the publishing of this article. The feedback, conversations and time spent with the author and the writing are greatly appreciated.

\section{Competing interests}

The author declares that she has no financial or personal relationships that may have inappropriately influenced her in writing this article.

\section{References}

Abbott, T.B., 2012, 'The trans/romance dilemma in Transamerica and other films', The Journal of American Culture 36, 32-41. https://doi.org/10.1111/jacc.12011

American Psychiatric Association (APA), 1994, Diagnostic and statistical manual of mental disorders (DSM-IV), 4th edn., American Psychiatric Association, Washington.

Butler, J., 1988, 'Performative acts and gender constitution: An essay in phenomenology and feminist theory', Theatre Journal 40(4), 519-531. https:// doi.org/10.2307/3207893

Cavalcante, A., 2013, "Centering transgender identity via the textual periphery: TransAmerica and "double work" of paratexts', Critical Studies in Media Communication 30(2), 85-101. https://doi.org/10.1080/15295036.2012.694077

De Beauvoir, S., 1988, The Second sex, Picador, Thetford.

Eleftheriotis, D., 2010, Cinematic journeys: Film and movement, Edinburgh University Press, Edinburgh.

Ganser, A., Pühriner, J. \& Rheindorf, M., 2006, 'Bakhtin's chronotope on the road: Space, time, and place in road movies since the 1970s', Facta Universitatis $4(1), 1-17$.

Green, E.R. \& Maurer, L.M., 2015, The teaching transgender toolkit: A facilitator's guide to increasing knowledge, decreasing prejudice and building skills, Out for health, Ithaca.

Greenblatt, E., 2006, Brokeback mountain, Capote, and Transamerica receive Oscars, viewed 18 December 2017, from Salem Press Encyclopedia (Ebsohost).

Hayward, S., 1996, Key concepts in cinema studies, Routledge, London.

Hebblethwaite, C., 2011, Sweden's 'gender-neutral' pre-school, viewed 23 September 2017, from http://www.bbc.com

Jordan, N., 1992, The crying game, DVD, Palace Pictures, London.

Laderman, D., 2002, Driving visions: Exploring the road movie, University of Texas, Austin, TX.

Lee, A., 2005, Brokeback mountain, DVD, River Road Entertainment, Los Angeles, CA.

Lips, H.M., 2006, A new psychology of women: Gender, culture, and ethnicity, 3rd edn., McGraw-Hill, New York.

Merskin, D., 2007, 'Truly toffee and raison hell: A textual analysis of lipstick names', Sex Roles 56, 591-600. https://doi.org/10.1007/s11199-007-9201-9

Nagoshi, J.L. \& Brzuzy, S., 2010, 'Transgender theory: Embodying research practice', Affilia: Journal of Women and Social Work 25(4), 431-443. https://doi.org/ 10.1177/0886109910384068

Namste, V., 2006, 'Transsexual, transgender, and queer: An interview with Vivian Namaste', in S. Seidman, N.L. Fischer \& C. Meeks (eds.), Handbook of the new sexuality studies, pp. 180-187, Routledge, London.

O'Reilly, S., 2009, The body in contemporary art, Thames \& Hudson, London.

Osteen, M., 2008, 'Noir's cars: Automobility and amoral space in American film noir', Journal of Popular Film and Television 35, 183-192. https://doi.org/10.3200/ JPFT.35.4.183-192

Peirce, K., 1999, Boys don't cry, DVD, IFC Films, New York.

Ryall, T., 1998, 'Genre and Hollywood', in J. Hill \& P. Church Gibson (eds.), The Oxford guide to film studies, pp. 327-343, Oxford University Press, Oxford.

Stryker, S., 2006, '(De)Subjugated knowledges: An introduction to transgender studies', in S. Stryker \& S. Whittle (eds.), The transgender studies reader, pp. 1-17, Routledge, New York.

Stutesman, D., 2005, 'Storytelling: Marlene Dietrich's face and John Frederic's hats', in R. Moseley (ed.), Fashioning film stars: Dress, culture, identity, pp. 27-38, BFI Publishing, London.

Tauches, K., 2006, 'Transgendering: Challenging the "normal"', in S. Seidman, N.L. Fischer \& C. Meeks (eds.), Handbook of the new sexuality studies, pp. 173-179, Routledge, London.

Tucker, D., 2005, Transamerica, DVD, Belladonna Productions, Manhattan.

Tucker, D., 2006, The shooting script: Transamerica, Newmarket Press, New York.

Waskul, D. \& Vannini, P., 2006, 'The body in symbolic interaction', in D. Waskul \& P. Vannini (eds.), Body/Embodiment: Symbolic interaction and the sociology of the body, pp. 1-18, Ashgate, Hampshire.

West, C. \& Zimmerman, D.H., 1987, 'Doing gender', Gender \& Society 1(2), 125-151. https://doi.org/10.1177/0891243287001002002 